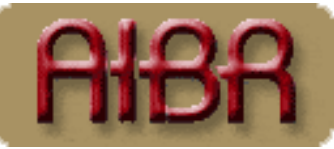

REVISTA DE ANTROPOLOGÍA IBEROAMERICANA

ESTIMADO LECTOR/A:

GRACIAS POR DESCARGAR ESTE ARTÍCULO. EL TEXTO QUE ESTÁ A PUNTO DE CONSULTAR ES DE ACCESO LIBRE Y GRATUITO GRACIAS AL TRABAJO Y LA COLABORACIÓN DESINTERESADA DE UN AMPLIO COLECTIVO DE PROFESIONALES.

USTED PUEDE AYUDARNOS A INCREMENTAR LA CALIDAD Y A MANTENER LA LIBRE DIFUSIÓN DE LOS CONTENIDOS DE ESTA REVISTA A TRAVÉS DE SU INSCRIPCIÓN A LA ASOCIACIÓN AIBR:

http://www.aibr.org/antropologia/aibr/socios.php

La asociación a AIBR tiene un coste mínimo al año, y le proporcionará las siguientes ventajas y privilegios:

1. Recibir en su domicilio la revista impresa, en Europa y América (tres números anuales), así como todas las novedades relativas al funcionamiento de la asociación.

2. Recibir en su domicilio, a precio especial o de forma gratuita, cuantas publicaciones adicionales edite la asociación.

3. Derecho a voto en las asambleas de socios, así como a presentarse como candidato a la elección de su Junta Directiva.

4. Recibir el boletín de socios (tres números anuales), así como la información económica relativa a cuentas anuales de la asociación.

5. Beneficiarse de las reducciones de precio en congresos, cursos, libros y todos aquellos convenios a los que a nivel corporativo AIBR llegue con otras entidades. En este momento, existen los siguientes acuerdos:

o Reducción de un $20 \%$ en el precio de todos los libros publicados por la editorial MELUSINA.

o Reducción de un $20 \%$ en el precio de todos los libros publicados por la editorial SEPHA.

o Reducción de un 30\% en el precio de todos los libros publicados por la editorial GRAN VÍA.

o Derecho a cuota reducida en los congresos trianuales de la FAAEE (España) y a los bianuales de la Sociedad Española de Antropología Aplicada.

o Derecho a cuota reducida en los congresos la IUAES.

6. Promoción gratuita, tanto a través de la revista electrónica como de la revista impresa, de aquellas publicaciones de las que sea autor y que estén registradas con ISBN. La difusión se realiza entre más de 5.000 antropólogos suscritos a la revista.

7. Cuenta de correo electrónico ilimitada de la forma socio@aibr.org, para consultar a través de webmail o cualquier programa externo.

8. Espacio para web personal de la forma http://www.aibr.org/(directorio)/(nombre) y cuenta propia de ftp.

9. Acceso con clave a todos los documentos de la Intranet de socios de AIBR, incluida la consulta a artículos en proceso de evaluación de la revista AIBR.

10. Promoción gratuita a través de la revista (banner rotativo y reseña) de aquellos eventos, congresos, conferencias o cursos en los que usted forme parte del comité organizador.

11. Opción a formar parte como evaluador de los artículos recibidos por la revista.

IMPORTE DE LA CUOTA ANUAL: Hasta diciembre de 2008, la cuota única anual es de 32 (euros). Su validez es de un año a partir del pago de la cuota. Por favor, revise la actualización de cuotas en nuestra web. 


\title{
A32 INMIGRACIÓN, SALUD Y GESTIÓN DE LA DIVERSIDAD: PRESENTACIÓN Y AVANCES PRELIMINARES DE UN PROYECTO EN BARRIOS DE CATALUÑA
}

\section{Dan Rodríguez-García ${ }^{1}$ y Teresa San Román Espinosa ${ }^{2}$}

\author{
${ }^{1}$ Profesor del Departamento de Antropología Social y Cultural de la Universidad Autónoma de \\ Barcelona (España) y Miembro del Grupo de Investigación en Antropología Fundamental y Orientada \\ (GRAFO). Dirección: Departamento de Antropología Social y Cultural, Universidad Autónoma de \\ Barcelona, Facultad de Letras, Edificio B, 08193 Bellaterra (Barcelona), España. E-mail: \\ dan.rodriguez@uab.es
}

${ }^{2}$ Catedrática del Departamento de Antropología Social y Cultural, Universidad Autónoma de Barcelona (España) y Directora del Grupo de Investigación en Antropología Fundamental y Orientada (GRAFO). Dirección: Departamento de Antropología Social y Cultural, Universidad Autónoma de Barcelona, Facultad de Letras, Edificio B, 08193 Bellaterra (Barcelona), España. E-mail: teresa.sanroman@uab.es

\begin{abstract}
Resumen
Este artículo describe sucintamente un proyecto de investigación en curso sobre inmigración, salud y diversidad sociocultural, ofreciendo información preliminar sobre el contexto teórico y sociodemográfico de la investigación. El objetivo del proyecto, que se enmarca dentro del Programa Salud en los Barrios del Departamento de Salud de la Generalitat de Catalunya (España), es analizar los factores socioeconómicos y culturales que inciden en la salud y la atención sanitaria de los colectivos inmigrantes y minorías étnicas que residen mayoritariamente en barrios de acción prioritaria de Cataluña: los factores que afectan a su salud, el acceso a los servicios sanitarios y a la relación que mantienen con ellos y con el personal sanitario que los atiende. Los resultados, obtenidos fundamentalmente a través de investigación etnográfica, pretenden orientar mejor la atención sanitaria y dotar a los profesionales de instrumentos conceptuales y prácticos para la detección de problemas, la prevención y resolución de conflictos, y la mejora de la comunicación intercultural.
\end{abstract}

\section{Palabras clave}

Inmigración, salud, diversidad socio-cultural, antropología aplicada, etnografía.

\begin{abstract}
This article presents an ongoing research project on immigration, health, and socio-cultural diversity, and offers preliminary information on the theoretical and sociodemographic context of this investigation. The objective of the project, funded by the Department of Health of the Autonomous Government of Catalonia, Spain, is to analyse the socio-economic and cultural factors involved in health and the access to the formal health system of a few major migrant communities and ethnic minorities living in high-priority neighbourhoods in Catalonia. The
\end{abstract}


results of this project, which will come fundamentally from ethnographic research, aim to give suggestions for improving health conditions for the population and to provide to those professionals working in the public health care system with some conceptual and practical tools for improving intercultural communication between themselves and their patients, as well as for detecting, preventing, and resolving problems in everyday practice.

Keywords

Immigration, Health, Socio-cultural diversity, Applied anthropology, Ethnography.

Agradecimientos

Agradecemos la colaboración de Miriam Torrens, Irina Casado, Hugo Valenzuela, Óscar López, Virginia Fons, Carmen Méndez, Meritxell Saez Sellarés y, especialmente, de Lucía Sanjuán.

Recibido: 17 de Junio de 2007

Aceptado: 24 de Agosto de 2007

\section{Introducción: contexto, objetivos y metodología del proyecto}

Uno de los campos de estudio crecientes en antropología es el que relaciona las migraciones y la interculturalidad con el ámbito de la salud en contextos urbanos. En este artículo se presenta de forma sucinta un proyecto de investigación en curso en Cataluña (España) sobre inmigración y diversidad sociocultural en el campo de la salud, y se ofrece información sociodemográfica y teórica de contexto. Se trata de un proyecto titulado "Desigualdades socioeconómicas y diferencia cultural en el ámbito de la salud en barrios de actuación prioritaria de Cataluña", que se inscribe en el marco de un convenio entre el Departamento de Salud de la Generalitat de Catalunya (gobierno autónomo) y el GRAFO (Grupo de Investigación en Antropología Fundamental y Orientada), que está constituido por investigadores y profesores del Departamento de Antropología Social y Cultural de la Universidad Autónoma de Barcelona, y que dirige la Dra. Teresa San Román. El proyecto tiene una duración de dos años (los resultados finales estarán disponibles previsiblemente en 2008) y cuenta con un grupo de etnógrafos dedicados a distintas comunidades 
inmigradas así como con el apoyo del Departamento de Antropología social y cultural de la UAB y la colaboración de los centros y el personal médico.

El proyecto se enmarca dentro del Programa Salut als Barris (Salud en los Barrios) del Departament de Salut, un programa que, a su vez, está dentro de la reciente Llei de Barris (Ley de Barrios) de la Generalitat, que se orienta a una acción integral en zonas de atención preferente, en las que concuerdan necesidades de tipo urbanístico con otras de tipo social y de salud. Las prioridades del programa son: 1) el análisis de los factores sociales y culturales que pueden producir desigualdades en salud; 2) el trabajo cooperativo con los ayuntamientos y ciertos centros de salud y de proximidad en la planificación, la acción y la evaluación, y 3) el impulso de la salud comunitaria, la prevención y la promoción de la salud.

El objetivo general de este proyecto de investigación es analizar los factores que inciden en la salud y la atención sanitaria de los colectivos inmigrantes y minorías étnicas que residen mayoritariamente en barrios de acción prioritaria (que tienen una cierta urgencia de acción urbana y socioeconómica) de Cataluña. La tarea fundamental de esta investigación es comprender la conjunción de las situaciones socio-económicas y los factores culturales correspondientes a diferentes segmentos en condiciones vulnerables de diversos colectivos que tienen una presencia importante en algunos de los barrios implicados en el Programa Salud Barrios y los factores que afectan a su salud, al acceso a los servicios sanitarios y a la relación que mantienen con ellos y con el personal sanitario que los atiende. Paralelamente a estos intereses fundamentales de investigación, se plantea realizar una tarea formativa de al menos una parte del personal sanitario que trata con estas poblaciones, y una tarea de información que considere la participación activa de las propias poblaciones a medio y largo plazo. En este sentido, el trabajo etnográfico juntamente con la reflexión y la contrastación sobre y a través de la práctica clínica, deben permitir mejorar este conocimiento y cumplir con el objetivo de fondo del proyecto, que es orientar mejor la atención sanitaria y dotar a los profesionales de instrumentos conceptuales y prácticos para la detección de problemas, la prevención y resolución de conflictos, la mejora de la comunicación profesional intercultural y la participación real comunitaria. Este objetivo deberá conseguirse trabajando de manera interdisciplinaria entre el equipo de investigación y los profesionales de la salud (médicos, enfermeros y enfermeras, técnicos, administrativos, etc.), 
especialmente los más directamente implicados y motivados. En suma, se trata de que los resultados de la investigación sean útiles para mejorar la práctica sanitaria cotidiana con colectivos inmigrados y minorías étnicas, y la comprensión de los complejos factores culturales, económicos y políticos que pueden intervenir en el tratamiento sanitario de estos usuarios, contribuyendo así a crear un sistema sanitario más eficaz y adaptado a la realidad actual.

Específicamente, el proyecto se propone elaborar informes etnográficos para conocer mejor a los colectivos inmigrados y/o minoritarios y facilitar la atención médica de estos en los barrios prioritarios. Se trata de conocer las situaciones y los problemas fundamentales de índole cultural, social, económica y jurídica que inciden en la salud de las poblaciones y en sus posibilidades de acceso y de utilización del sistema sanitario de Cataluña y señalar los factores que están incidiendo en las disfunciones respecto a una adaptación óptima en estos aspectos y en el correcto funcionamiento de los servicios. Para ello, es necesario:

a) Conocer los aspectos culturales fundamentales en cuanto a las representaciones, valoraciones y comportamientos sobre el concepto de persona, el cuerpo y la psique, los componentes del cuerpo y su relación, la concepción de la vida, la muerte y la reproducción humana, así como de la salud y la enfermedad; la interpretación del dolor y sus causas y la escala y gravedad con la que se valoran; la concepción de las terapias, de los terapeutas y de las relaciones idóneas entre ellos; las ideas y experiencias respecto a la compatibilidad de diversos tipos de tratamientos y terapias, desde la biomedicina a la tradicional, pasando por las alternativas y la instaurada por la OMS en los países de origen, la pública y la privada, los accesos, la posible combinación de sus usos y los diferentes tipos de valor y utilidad adjudicados a cada una de ellas; y conocer y valorar también la existencia y eficacia de las redes de apoyo potencial de las personas en relación con la salud.

b) Conocer las situaciones económicas, sociales y culturales que han sido fundamentales en la decisión de emprender el viaje migratorio; los compromisos o hipotecas económicas, sociales y afectivas que ha comportado; las características del proceso migratorio y el asentamiento; la historia laboral, socioeconómica y cultural del asentamiento; la situación actual; las formas de relación con el lugar de origen (con su grupo étnico concreto y con otros); las relaciones vecinales, laborales y de ocio con los diferentes segmentos sociales y étnicos de nuestra sociedad y las ideas y prejuicios al respecto; la experiencia de racismo, segregación u otras formas de prejuicio; el proyecto de permanencia/retorno y las valoraciones y actitudes sobre la vida en origen y en destino. En todo esto existen aspectos que se relacionan con la salud física y psicológica y con la satisfacción o sentimiento de fracaso, con las habilidades de inserción social y de uso de los servicios y las capacidades de 
comunicación y, en suma, con variables de integración sociocultural que son cruciales para entender cómo y porqué se piensa y se actúa de cierta forma.

c) Valorar el conocimiento inicial del que parten los profesionales de la salud respecto a estas cuestiones e identificar conjuntamente los segmentos afectados en diferentes niveles y aspectos, las características, los problemas y los factores que pueden pensarse inicialmente que los causan. Es decir, conocer tanto la experiencia como la percepción, preocupación y actitudes de los profesionales que trabajan directamente sobre el terreno con estos colectivos.

d) Construir algunos instrumentos de orientación en este campo que se puedan poner al alcance del personal sanitario implicado a diferentes niveles y otros que puedan servir a los propios usuarios y a las personas de su entorno. Por ejemplo, proponer categorías, indicadores e instrumentos flexibles y adaptados de detección de problemas, una guía intercultural para el uso del personal sanitario y otra para los diferentes usuarios y realizar una contrastación inicial de estos instrumentos.

e) Realizar una campaña informativa y de sensibilización dirigida a la propia población objeto del estudio por parte de un equipo interdisciplinario que reuniría personal sanitario y miembros del GRAFO de la UAB y con ayuda y participación activa de personas de las entidades cívicas de los colectivos y barrios implicados que se consideren idóneas.

f) Ofrecer a la Administración recomendaciones para las líneas de actuación respecto a los usuarios marginados o en riesgo de marginación y culturalmente diversos, que estén bien fundamentadas desde el punto de vista del conocimiento (investigación de los problemas de salud en sus contextos, cualitativa y cuantitativa, contrastada empíricamente y valorada teóricamente) y que se construya con la participación de profesionales de la salud de diversos estamentos bien seleccionados y fuertemente motivados. Orientar así líneas de actuación y poner sobre aviso medidas y líneas contraproducentes.

g) Formar a un pequeño núcleo de personal sanitario con habilidades de comprensión y de comunicación general intercultural, capaz de manejar técnicas de toma de datos y de análisis cualitativo y familiarizado con conocimientos básicos sobre las culturas y las condiciones y procesos sociales, económicos y culturales de estas poblaciones. La formación se plantea de forma que el discurso esté estrechamente vinculado con la práctica profesional y con un contenido de reflexión/acción sobre la práctica sanitaria en el contexto social y cultural concreto.

h) Plantear bases para la participación de las poblaciones implicadas y de las entidades cívicas y de las propias de los colectivos, que tenga como objetivo la implicación en los programas y acciones que se puedan llevar a cabo en el ámbito de la salud, servir de vehículos para la concienciación y derivación hacia las instituciones sanitarias de los problemas de la población en este campo, que busquen el entendimiento y la colaboración entre ellas mismas. 
El ámbito de estudio de esta investigación son algunos de los barrios incluidos en el Programa Salud Barrios del Departamento de Salud de la Generalitat de Catalunya, todos ellos multiétnicos y con poblaciones de bajos recursos, y seleccionados por su idoneidad para los propósitos del estudio.

Las poblaciones seleccionadas son las poblaciones inmigradas de origen marroquí, pakistaní, diversos grupos subsaharianos de Senegal, de Gambia y de Guinea Ecuatorial, inmigrantes de Europa del Este (principalmente rumanos), gitanos rumanos inmigrantes, gitanos catalanes y gitanos originariamente inmigrados de otras zonas del Estado. Ninguna de estas poblaciones puede definirse como población marginal o en situación precaria económica y socialmente en su integridad. El estudio se limita a aquellos segmentos que están en situación marginal o en riesgo de marginación. Cabe señalar que el punto de partida de la selección de los grupos ha seguido los siguientes criterios: las necesidades planteadas por los profesionales de la salud; que fueran grupos que se encuentran de forma extensa en los barrios prioritarios; y que hubiera algún etnógrafo/a vinculado al proyecto con suficiente conocimiento como para llevar a cabo la investigación etnográfica sobre ese grupo. Estos criterios han hecho que ciertos grupos (por ejemplo, colectivos latinoamericanos o chinos) hayan quedado fuera en este primer estudio. Relacionadamente, el conjunto de barrios y grupos seleccionados es el siguiente ${ }^{1}$ :

\begin{tabular}{|c|c|c|c|}
\hline BARRIO & MUNICIPIO & COMARCA & GRUPO \\
\hline \multirow{2}{*}{ Poble Sec } & \multirow{2}{*}{ Barcelona } & \multirow{2}{*}{ Barcelonés } & Rumanos y \\
\hline & & & Pakistaníes \\
\hline Collblanc Torrassa & L'Hospitalet & Barcelonés & Gitanos rumanos \\
\hline Sant Roc & Badalona & Barcelonés & Gitanos rumanos \\
\hline Ca n'Anglada & Terrassa & Vallès Occidental & Gitanos y Pakistaníes \\
\hline Parc fluvial riu Ripoll & Sabadell & Vallès Occidental & Gitanos rumanos \\
\hline Can Folguera & $\begin{array}{l}\text { Sta. } \\
\text { Mogoda }\end{array}$ & Vallès Occidental & Gitanos \\
\hline Sant Cosme & El Prat de llobregat & Baix Llobregat & Gitanos \\
\hline Barris Sud & Vic & Osona & Magrebíes \\
\hline Barri de l'Erm & Manlleu & Osona & Magrebíes \\
\hline
\end{tabular}

${ }^{1}$ La información etnográfica de las poblaciones inmigradas de Senegal y de Gambia parte de estudios etnográficos previos de Adriana Kaplan y T. San Román, miembros del equipo de investigación.. 


$\begin{array}{llll}\text { Centre històric } & \text { Balaguer } & \text { Noguera } & \text { Rumanos } \\ \text { Casc antic } & \text { Tortosa } & \text { Baix Ebre } & \text { Gitanos rumanos } \\ \text { La Mariola } & \text { LLeida } & \text { Segrià } & \text { Gitanos } \\ \text { Nucli antic } & \text { Manresa } & \text { Bages } & \text { Gitanos }\end{array}$

FIGURA 1. Conjunto de barrios y grupos seleccionados

La metodología utilizada es la propia de la antropología social y cultural: métodos etnográficos que implican la observación y participación, el establecimiento general de un marco sociocultural holista (en origen y en destino, mediante análisis bibliográfico y trabajo de campo) y el diseño de técnicas más específicas de recogida de información de primera mano, orientado a la comprensión de las cuestiones de salud integradas en el contexto vital y sociocultural de las personas en y desde sus barrios. Se trata de hacer converger los datos estadísticos disponibles con los datos empíricos extraídos directamente de la realidad de los colectivos en cuestión en diferentes contextos: contexto médico, asociaciones, familias, encuentros informales, etc. La información relevante a obtener incluye, entre otras cosas: las ideas respecto a la procreación de los seres humanos y la concepción de la persona, las normas y usos relativos a la sexualidad reproductiva, las ideas respecto a la enfermedad psíquica y física, las prácticas curativas formales e informales, las enfermedades frecuentes en colectivos concretos, el rol de los parientes ante la enfermedad, los factores religiosos que afectan al paciente y a su tratamiento, etc.

Las técnicas cualitativas concretas, flexibles y adaptadas a las características de cada colectivo y situación, son las siguientes:

a) Observación directa y continuada a lo largo de todo el proyecto en los contextos de interés para la comprensión amplia de situaciones y poblaciones seleccionadas.

b) Entrevistas a expertos (personas que se ocupan y preocupan especialmente de las cuestiones de salud de estas poblaciones y con larga experiencia).

c) Entrevistas abiertas y en profundidad con una guía para la observación de los temas más interesantes para el estudio detectadas en el trabajo de campo y en las conversaciones con personal sanitario.

d) Grupos focales, una vez que se haya conocido el contexto y que la selección de participantes esté claramente justificada.

e) Construcción de itinerarios terapéuticos vitales o desde el momento de su migración, considerando su uso de la medicina pública y privada, sus diferentes tipos de servicios y el 
eventual recurso a expertos en saberes y terapias tradicionales y alternativas, atendiendo a la forma y razones para elegir y combinar estos tipos de recursos.

f) Redes de apoyo personal potenciales y activas de las personas objeto del estudio, de manera que los vínculos y los nodos se cualifiquen también con criterios relacionados con el ámbito de la salud, además de los obvios del tipo de relación.

g) Seguimiento individualizado de los procesos de algunas personas con problemas de salud en todos los contextos en los que participen (familia, barrio, trabajo, institución sanitaria, "especialistas sanitarios" no reconocidos oficialmente, lugares de culto o educativos, etc.

Aunque se enfatiza el aspecto cualitativo, los objetivos del proyecto requieren el uso de metodologías mixtas, incorporando el también el análisis cuantitativo, cuya utilidad es mayor en el tramo final del trabajo de campo, cuando la familiaridad con el contexto y las situaciones, permiten plantearse una codificación idónea para la cuantificación sin perder de vista significados y contextos a la hora de clasificar. El proyecto parte de un estudio preliminar de los colectivos y barrios seleccionados que aporta una lectura antropológica de los documentos pertinentes disponibles (documentación pertinente del programa de Salud Barrios, otra documentación de otras fuentes de la Generalitat, de los ayuntamientos a los cuales pertenecen los barrios seleccionados y de otros centros, y otros documentos sobre programas, proyectos, ordenanzas, informes, etc.). Asimismo, incluye entrevistas puntuales a informantes clave (técnicos de la administración, asistentes y trabajadores sociales, técnicos de salud, mediadores, líderes locales y especialistas locales en salud). Estas actividades han de proporcionar datos básicos para la orientación global del proyecto sobre los diferentes colectivos (datos sobre inmigración y minorías) y su hábitat concreto, atendiendo a las condiciones generales sociales y urbanísticas y a aspectos de especial relevancia para este proyecto (por ejemplo, pautas de reagrupación familiar y ciclos y pautas de relación en la inmigración y el asentamiento, en gitanos marginados o muy pobres, pautas de movilidad, etc.).

En cuanto a la etnografía, la selección de los barrios se ha hecho en función de las exigencias etnográficas de los colectivos que se van a estudiar, centrándose en aquellos que pueden resultar más cultural y socialmente inaccesibles. Los etnógrafos llevan a cabo este trabajo, sin perder de vista los contextos particulares y generales de la problemática estudiada, los significados y las relaciones entre los distintos factores en juego. Al lado de éstos, desde el principio, están algunos profesionales de la salud con suficiente conocimiento de estos contextos y de la 
investigación antropológica y social, de manera que su presencia y, con ella, la de los problemas que se les están planteando a los profesionales y las instituciones de la salud, estén a la vista para poder analizarlos. Esto repercutirá también en su formación en este campo.

\section{Aproximaciones teóricas y sociodemográficas}

\subsection{Salud, Inmigración y Diversidad Cultural}

Como veremos detalladamente en el siguiente apartado, Cataluña es una de las comunidades autónomas que recibe más inmigración del Estado, y no se espera que esta tendencia disminuya en los próximos años, dejando claro que no se trata de un fenómeno coyuntural, sino de una realidad con efectos estructurales (políticos, económicos, demográficos, socio-culturales) que cabe gestionar, y que representa el motor de transformación social más importante a corto, medio y largo plazo.

Ciertamente, esta nueva inmigración, y los aspectos económicos y de diversidad sociocultural que introduce, genera unas nuevas demandas por parte de la población en general que hay que atender, y se ha convertido en uno de los elementos cruciales que, juntamente con el envejecimiento de la población y los cambios en la relación de dependencia y los roles familiares, conforman las bases para un nuevo escenario socio-sanitario en Cataluña. Esta interrelación de poblaciones de orígenes diversos no afecta sólo al ámbito económico o laboral, sino que también crea una nueva realidad en el ámbito sanitario, planteando nuevos e importantes retos, que a su vez requieren nuevas estrategias y una gestión adecuada. A diferencia de países como Estados Unidos, Canadá o Inglaterra, con más tradición en la recepción de inmigración internacional, las repercusiones de esta nueva situación en el ámbito socio-sanitario han empezado a estudiarse sólo recientemente en nuestro país. En este contexto, cada vez es más común oír hablar de: multiculturalidad en el ámbito de la salud; medicina y enfermería transcultural; etno-enfermería; pluralismo médico; sistema integrador o híbrido (versus biomédico o alopático) de salud; perspectiva holística e integradora de la salud; medicina complementaria; mediación intercultural en salud, etc. 
Algunas de las nuevas situaciones que plantea la nueva inmigración tienen que ver con la vulnerabilidad ante la enfermedad, especialmente ante las infecciones; la dificultad de acceso a los servicios normalizados de salud; el desconocimiento de los inmigrantes del funcionamiento del sistema sanitario en la sociedad de acogida, que conduce a un uso poco adecuado de los servicios, con incumplimiento de horarios, recurso generalizado a los servicios de urgencias, etc.; y la dificultad para el cumplimiento de los tratamientos y para participar en actividades de educación y promoción de la salud. Por un lado, los profesionales sanitarios se quejan de la resistencia de los inmigrantes y minorías étnicas al seguimiento de las recomendaciones terapéuticas en relación con el diagnóstico y las prácticas rutinarias de prevención en salud; de las quejas indefinidas; de la dificultad, en ocasiones, en los exámenes médicos y el seguimiento posterior; de la barrera idiomática (que incluye el analfabetismo, al menos en nuestro alfabeto e idioma); $y$, en general, de la sobrecarga de los equipos de salud en el momento actual de aumento del volumen y heterogeneidad de los pacientes. A menudo se pasa por alto que muchos de estos problemas tienen que ver, sobre todo, con la necesidad de implementar los recursos de la administración y de mejorar las estrategias de gestión ante una situación sociodemográfica que ha cambiado radicalmente en muy poco tiempo. Por otro lado, los inmigrantes y miembros de minorías étnicas se quejan de que los profesionales de la salud no conocen su cultura ni condiciones socio-económicas; que no les dedican suficiente tiempo y atención; y también se quejan de la barrera idiomática, que les dificulta la comunicación y que afecta a todo el proceso de seguimiento en salud.

Hacen falta, sobre todo, canales de información y de conexión y entendimiento entre las dos partes, inmigrantes y profesionales de la salud; en general, entre la sociedad civil y las administraciones. Las dificultades de comunicación y la falta de adaptación de los servicios a la realidad social y cultural de sus usuarios afectan a la calidad de la atención sanitaria en diversos frentes: la calidad de la "anamnesis" (la información proporcionada por el paciente al médico durante una entrevista clínica, con la finalidad de incorporarse a la historia clínica del paciente); el retraso en la identificación de síntomas y diagnóstico; el tratamiento y seguimiento de los casos y cumplimiento del tratamiento prescrito por problemas de interpretación; el abandono en el seguimiento del tratamiento y de las visitas, etc. En 
este sentido, la mediación intercultural en salud se perfila como uno de los instrumentos para mejorar la atención a la salud entre la población inmigrada. Hablamos aquí no sólo de la traducción de un idioma a otro, sino de un conjunto de acciones dirigidas a superar las limitaciones lingüísticas y socioculturales que afectan a la calidad, la eficiencia y la equidad en la atención sanitaria, y también su influencia sobre el estado de salud del grupo inmigrante, y que consta de tres ejes: paciente, profesional de la salud y traductor e intermediario o mediador. El mediador, por tanto, es un puente que favorece la comunicación y promueve un cambio constructivo en las relaciones entre personas socioculturalmente diversas, orientando su acción hacia la prevención y resolución de los conflictos individuales, familiares o comunitarios. Aunque en la actualidad hay diversos programas en marcha, aún hay un déficit tanto de profesionales de la mediación en el ámbito de la salud, como del reconocimiento de la importancia del apoyo de expertos en interculturalidad dentro de este ámbito. Será necesario invertir en la formación de los profesionales de la salud en materia de atención sanitaria transcultural (conocimiento sobre diversidad cultural, etc.), y elaborar material de información sanitaria traducido a diferentes idiomas (algo que está muy elaborado en países como Canadá), tal como prevé el actual Plan Director de Inmigración en Salud de la Generalitat de Catalunya.

Los estudios que se han hecho en Cataluña sobre inmigración y salud (véase la bibliografía temática al final del artículo) se han centrado, por un lado, en el análisis del propio sistema, de las limitaciones para dar respuesta a la nueva realidad, y de los nuevos servicios que se están implementando (acogida, acomodación, ámbito de mediación, etc.); y por otro lado, en aspectos de atención a la salud de poblaciones inmigradas y minorías, que se pueden resumir en los siguientes ámbitos:

1) Salud sexual, reproductiva y materno-infantil (incluye aspectos como la cobertura de vacunas, la asistencia al embarazo, parto y post-parto, mutilaciones genitales, adopciones internacionales, etc.)

2) Enfermedades infecciosas, importadas o adquiridas en la sociedad de acogida, y parasitarias (incluye aspectos como la malaria, la tuberculosis, el SIDA, etc.)

3) Salud mental (incluye aspectos como el duelo migratorio, el estrés múltiple y las somatizaciones). 
En síntesis, las particularidades en la situación de la salud para los inmigrantes tienen que ver con un conjunto de factores que incluyen: a) las características peculiares de su lugar de origen (hábitos dietéticos, hábitos en la salud materno-infantil, rasgos culturales, condiciones socioeconómicas deficitarias, enfermedades endémicas, etc.); b) el proceso migratorio, especialmente en el caso de la inmigración de países pobres y sobre todo en casos de refugio y asilo (agotamiento físico y emocional, estrés, depresión, condiciones deficientes de salubridad en origen, etc.); c) los problemas de integración en la sociedad de acogida (falta de inserción laboral y falta de ingresos, problemas de acceso a la información, segregación y marginación o exclusión territorial y social, etc.); d) las características estructurales del sistema sanitario y la falta de adaptación de los servicios.

En este contexto, resulta fundamental tener en cuenta la perspectiva antropológica, pues permite, entre otras cosas, comprender las diferencias socioculturales en las formas de percibir la salud y la enfermedad. Las concepciones, actitudes, conductas y comportamientos entorno a la salud son socialmente y culturalmente construidas. $\mathrm{Y}$ esto está conectado con las ideas respecto a la formación de los seres humanos, las normas y usos relativos a la crianza y cuidado de los individuos, los roles sociales por edad y género, la conceptualización de la enfermedad, de lo que es bueno/malo, sano/insano, etc. Esto implica tener en cuenta no sólo al individuo, como si fuera un elemento aislado, sino también su vinculación con el grupo o comunidad social y cultural. Por eso resulta del todo necesario un conocimiento de primera mano, etnográfico o "desde dentro", de la realidad y las características socio-culturales de las poblaciones inmigradas y minorías étnicas. Así, por ejemplo, entre los pueblos de origen asiático tradicionalmente la enfermedad y la salud se conciben de una forma más holística (equilibrio de energías o humores, frío/calor, etc. en donde influyen todos los aspectos de la vida, como la alimentación, el movimiento/descanso, el entorno, o las emociones) y menos centrado en la causa-efecto y el tratamiento farmacológico de efecto rápido del modelo hegemónico biomédico y tecnificado o alopático occidental. Tampoco hay en la tradición oriental una distinción estricta entre cuerpo y mente. $Y$ en el caso de poblaciones musulmanas, tanto de Asia, como por ejemplo Pakistán, o de África, como por ejemplo Marruecos o Senegal, la influencia del Islam en la 
concepción y tratamiento de la salud es también grande, tanto por la no estricta dicotomía entre mente y cuerpo, como por la relación entre el estado de salud y lo sagrado (muchas veces la enfermedad se atribuye al castigo divino). Asimismo, en el caso de los pakistaníes, como también ocurre entre poblaciones de África subsahariana, es necesario considerar el trinomio asociativo entre sexualidad, matrimonio y descendencia, que vertebra las relaciones de género, y la marcada división de los roles de género y edad. ${ }^{2} \mathrm{O}$ en las poblaciones procedentes del África subsahariana, por ejemplo, debe tenerse en cuenta la organización de la procreación y las estructuras domésticas en origen, y importancia de la familia y la red social y la concepción de la persona no como un individuo aislado, sino como parte de un colectivo (familia, red de parientes y amigos, etc.), así como aspectos más generales de relación entre las personas y el mundo como, por ejemplo, la falta de una distancia tan estricta como en occidente entre mundo visible y mundo no visible y la creencia (vivencia) de las fuerzas invisibles latentes, que está en la base de la concepción misma de la realidad y también de la salud y la enfermedad. Otras características particulares pueden tener que ver con tradiciones alimentarías distintas, como es el caso de la comida muy condimentada y el uso generalizado del picante propio de muchas poblaciones africanas y asiáticas, y a veces, como en el caso de los pakistaníes, con alto contenido graso, lo que parece influir en una mayor presencia de enfermedades coronarias y diabetes.

A la vez, sin embargo, cabe insistir, también desde la antropología, que no todo se explica desde la cultura, pues no todas las prácticas tienen en la cultura per se su razón de ser. Por un lado, es importante tener presente que muchos de los problemas de salud de las poblaciones inmigradas, y sus actitudes hacia la salud y los servicios sanitarios, son muy parecidos a los del resto de la población autóctona. Por otro lado, a pesar de que los inmigrantes son mayoritariamente personas jóvenes y sanas, a menudo viven en condiciones precarias socialmente, laboralmente y económicamente, hecho que los convierte en una población vulnerable a los problemas de salud derivados de las desigualdades en las condiciones de vida (vivienda, educación, ámbito laboral, situación de irregularidad,

\footnotetext{
${ }^{2}$ Es preciso señalar que, aunque el islam regula todos los aspectos de la vida del creyente y estipula el modelo de relaciones de género, la desigualdad de género es más un efecto de la estructura patriarcal pos-colonial y de la politización de la religión que de la religión en sí misma, que puede ser interpretada para legitimar los privilegios de unos y no de otras.
} 
etc.). Por tanto, los factores socioeconómicos (limitación de ingresos, pobreza, formación, etc.) pueden ser cruciales. No son pocos los expertos que señalan que, de hecho, en los barios con peores condiciones socio-sanitarias, los inmigrantes presentan los mismos problemas de salud que el resto de la población y que, en cambio, aquellos aspectos particulares, como las patologías tropicales, no tienen una predominancia significativa. Cabe evitar, pues, la culturalización o etnificación de las situaciones sociales, para no confundir diferencia cultural con desigualdad social. En todo caso, se trata de analizar la interrelación entre los diferentes factores, ya que no van necesariamente separados, sino que frecuentemente se explican los unos con los otros.

En cualquier caso, es primordial tener presente que, también en este ámbito de atención a la salud, la integración adecuada de las poblaciones inmigradas y minoritarias implica necesariamente una acomodación bi-direccional; es decir, que son las dos partes, los que ya están y los que llegan, las que han de cambiar cosas. Asimismo, será importante tener en cuenta que muchos aspectos que pueden parecer contradictorios a priori, no lo son ni tienen porqué serlo en la práctica. Por ejemplo, el modelo tradicional y el biomédico no entran necesariamente en contradicción, y que incluso pueden solaparse, porque se pueden utilizar para cosas distintas o momentos distintos del proceso (remedio, prevención, tratamiento, etc.).

\subsection{Contexto general de la inmigración en Cataluña}

La rapidez con la que España ha dejado de ser un país de emigración y se ha convertido en un país de inmigración no tiene precedentes en la historia demográfica europea, y quizás mundial. Mientras que en los países del norte de Europa, como Francia o Inglaterra, este cambio se produjo en varias décadas (entre los años 1950s y 1970s), en el caso español el panorama ha cambiado radicalmente en poco más de cinco años. De hecho, España es el país de la Unión Europea que ha experimentado el mayor incremento de inmigración ininterrumpidamente desde 1997, recibiendo en el año 2006 casi el 45\% de toda la población inmigrante que llegó a la UE. Es más, en los últimos seis años España se ha situado sólo por detrás de Estados Unidos en la intensidad de flujos migratorios a nivel mundial. De modo que, a pesar del lento inicio, desde el año 2000 la inmigración ha marcado de forma 
crucial la agenda política española, dejando claro que no se trata de un fenómeno coyuntural ni de una cuestión puramente técnica y administrativa, sino de una realidad con efectos estructurales (políticos, económicos, demográficos, socioculturales) que cabe gestionar.

El Padrón Municipal de Población a 1 de enero de 2006, registraba en España 4.144.166 residentes extranjeros empadronados (incluyendo a los que en esa fecha no tenían permiso de residencia), lo que representa el 9,3\% de la población total española (44.708.964). Y los datos provisionales del Padrón para el 1 de enero de 2007 señalan que el número de extranjeros ha aumentado a 4.482 .568 , casi el $10 \%$ de la población total (sin contar a los nacidos en el extranjero de nacionalidad española). Cataluña, una de las comunidades autónomas que recibe más inmigración del Estado, registraba, a 1 de enero de 2006, 913.757 residentes extranjeros empadronados, que representaban el $12,8 \%$ de la población total (7.134.697). Y los datos provisionales del Padrón para el 1 de enero de 2007 indican que el número alcanza ya 966.004 personas, que representan el $21,5 \%$ de la población extranjera del Estado y el $13,4 \%$ de la población total catalana. Esto convierte a Cataluña no sólo en una región de inmigración extraordinaria dentro del contexto del Estado, sino también en una de las regiones receptoras de inmigración de primera relevancia internacional. Y, a pesar de la concentración en algunas provincias y municipios, el hecho es que cada vez hay menos municipios en Cataluña, tanto de las áreas urbanas como de las rurales, que no estén afectados por la inmigración extranjera.

El panorama de la inmigración en Cataluña está influenciado por las tendencias de la inmigración internacional a nivel global, que no sólo se caracteriza por la globalización o mundialización y aceleración de los flujos, sino también por la diversificación de los orígenes y tipos migratorios. En este sentido, a pesar de que la inmigración procedente de la Unión Europea aún representa un porcentaje muy importante del total, en los últimos años se ha producido una gran diversificación de los países de origen, ofreciendo cada vez un mosaico más heterogéneo. Si hasta hace poco el origen primordial eran los países de la Unión Europea y del Magreb, particularmente de Marruecos, en la actualidad nacionalidades tan diversas como Ecuador, Rumania, Pakistán, China o Gambia tienen una presencia cada vez más importante en Cataluña (véanse las FIGURAS 2 y 3). En este sentido, se consolida 
en Cataluña, y en general en España, el característico doble flujo migratorio, de "países ricos" y de "países pobres", una diversificación que afecta a todos los ámbitos sociales (laboral, educativo, sanitario, etc.).

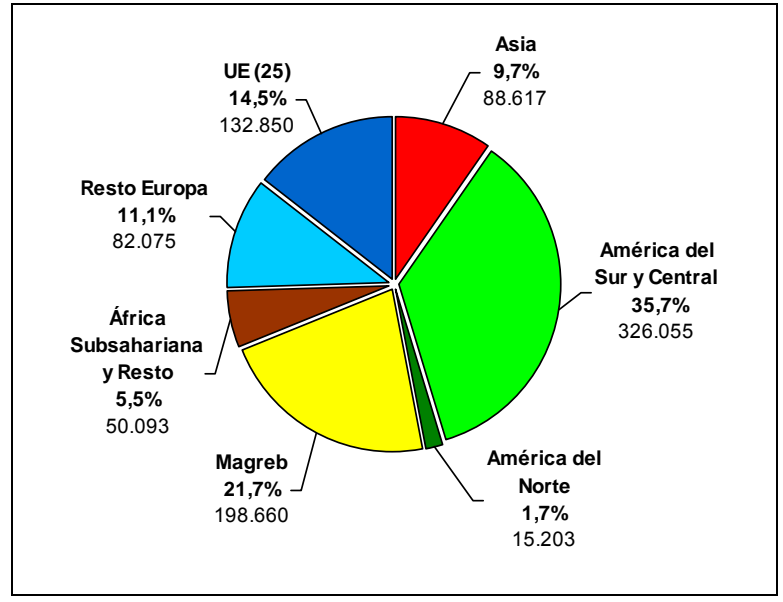

FIGURA 2. Población extranjera en Cataluña por zona de procedencia a 1/1/2006.

Fuente: Padrón Municipal de Población 2006, INE. Elaboración propia.

\begin{tabular}{ll} 
Nacionalidad & Total \\
\hline Marruecos & 188.604 \\
Ecuador & 86.710 \\
Rumania & 51.353 \\
Colombia & 43.228 \\
Bolivia & 35.387 \\
Argentina & 37.976 \\
China & 34.791 \\
Italia & 31.914 \\
Perú & 29.544 \\
Francia & 25.402 \\
Pakistán & 25.728 \\
Alemania & 18.790 \\
Reino Unido & 16.458 \\
Rep. Dominicana & 16.710 \\
Gambia & 14.329
\end{tabular}

FIGURA 3. Población extranjera en Cataluña por ranking de nacionalidades a 1/1/2006 Fuente: Padrón Municipal de Población 2006, INE. Elaboración propia.

Finalmente, en cuanto al impacto de la inmigración, cabe añadir que más del $60 \%$ de la inmigración que llega a Cataluña es joven (entre 19 y 44 años), hecho que, junto con una tasa de natalidad más alta de la población nativa (los nacimientos de madre extranjera suponen ya el $14 \%$ del total), está teniendo un importante 
efecto de rejuvenecimiento de la población, que afecta a todos los ámbitos sociales, incluido el de la salud (véase la FIGURA 4).
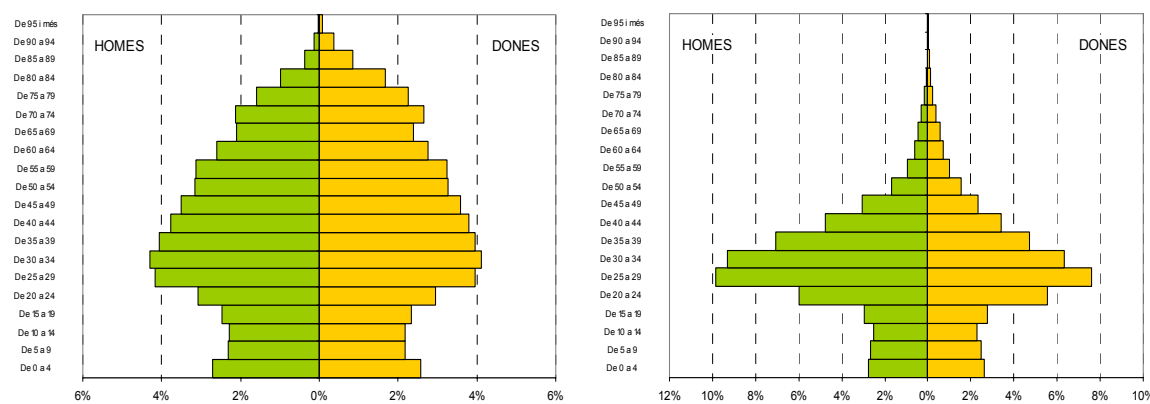

FIGURA 4. Pirámides de la población de nacionalidad española (izquierda) y extranjera (derecha) empadronada en Cataluña a 1/1/2006. Fuente: Secretaria per a la Immigració, Generalitat de Catalunya (datos no oficiales). Elaboración: Domingo y Gil (2006).

\subsection{Aproximación sociodemográfica a los municipios, barrios y grupos seleccionados}

De entrada, cabe señalar que hay muchas limitaciones de acceso a la información detallada y actualizada de los barrios y grupos seleccionados. Por un lado, la visibilidad estadística de algunos de estos grupos es muy limitada: por ejemplo, en el caso de los gitanos catalanes y originarios de otras zonas del Estado, se trata de minorías étnicas, pero no de extranjeros ni de inmigrantes, por tanto no quedan registrados ni por nacionalidad ni por país de origen en las estadísticas oficiales. También gran parte de la población inmigrada, especialmente la procedente de África, es poco visible estadísticamente, debido a que muchos están en situación legal irregular.

Por otro lado, hay muchas limitaciones en el acceso a los datos publicados a nivel de desagregación "barrio". Con excepción de unos pocos municipios, como por ejemplo Barcelona, a menudo los datos a nivel de barrio no se publican, y si están disponibles, no suelen estar actualizados. Además, frecuentemente los municipios siguen criterios diferentes para el registro de la población, con categorías territoriales que no siempre coinciden con la de los barrios seleccionados. Por ejemplo, las categorías "sección estadística", "zona estadística" o "distrito", no equivalen ni están formadas exactamente por barrios, sino por una agregación de las unidades más pequeñas. A todo esto, hay que añadir la protección estadística de los datos, que 
hace que la lectura de los códigos específicos, cuando la información está disponible, a menudo no pueda hacerse de forma directa.

Teniendo en cuenta estas limitaciones, lo que sigue son sólo algunas pinceladas aproximativas a la realidad sociodemográfica de los colectivos y barrios seleccionados, habiendo hecho una selección de algunos ejemplos donde la información indirecta disponible hasta el momento lo permitía. La información detallada sobre las características de los grupos y barrios seleccionados requerirá en gran medida del trabajo etnográfico de la fase en curso de la investigación.

En cuanto a las características generales de la inmigración en los barrios y municipios seleccionados, en la mayoría de ellos encontramos una presencia importante de inmigración extranjera. Aunque es en Barcelona donde hay más inmigración en términos absolutos, municipios como Hospitalet del Llobregat, Vic o Manlleu registran una densidad de población extranjera mucho más alta (véase la FIGURA 5).

\begin{tabular}{cccc} 
Municipios & $\begin{array}{c}\text { Total } \\
\text { Población }\end{array}$ & $\begin{array}{c}\text { Total } \\
\text { Extranjeros }\end{array}$ & $\begin{array}{c}\% \\
\text { Extranjeros }\end{array}$ \\
\hline BARCELONA & 5.309 .404 & 645.737 & 12,2 \\
Barcelona & 1.605 .602 & 244.988 & 15,2 \\
Hospitalet de Llobregat & 248.150 & 41.712 & 16,8 \\
Badalona & 221.520 & 29.345 & 13,2 \\
Terrassa & 199.817 & 22.479 & 11,2 \\
EI Prat de Llobregat & 63.069 & 4.868 & 7,7 \\
Sta. Perpètua de & & & \\
Mogoda & 21.644 & 1.384 & 6,4 \\
Manresa & 71.772 & 8.854 & 12,3 \\
Vic & 38.747 & 8.510 & 22,0 \\
Manlleu & 19.979 & 4.083 & 20,4 \\
LLEIDA & 407.496 & 52.633 & 13,0 \\
Lleida & 125.677 & 17.239 & 13,7 \\
Balaguer & 15.769 & 2.710 & 17,2 \\
TARRAGONA & 730.466 & 99.103 & 13,5 \\
Tortosa & 34.266 & 5.751 & 16,7
\end{tabular}

FIGURA 5. Población extranjera en Cataluña por provincias y municipios seleccionados a 1/1/2006.

Fuente: Padrón Municipal de Población 2006, INE. Elaboración propia. 
Empezando por la ciudad de Barcelona, a fecha de 1 de enero de 2006, había empadronados 244.988 extranjeros, que representaban el $15,2 \%$ del total de la población empadronada (por encima de la media de la provincia de Barcelona, $12,2 \%$, y del conjunto de Cataluña, 12,8\%). A pesar de que el distrito de Ciutat Vella es donde se concentra más población extranjera tanto en números absolutos como en términos relativos, hay otros distritos, como Nou Barris, Sant Martí o SantsMontjuïc-que alberga el barrio de Poble Sec-donde la población extranjera ha crecido más en los últimos años (véase la Figura 6). De hecho, según datos del Servicio de Estadística del Ayuntamiento de Barcelona, los distritos que tienen un peso de población extranjera por encima de la media de la ciudad (15\%) son, en este orden: Ciutat Vella $(38,5 \%)^{3}$, Sants-Montjuïc $(17,8 \%)$ y Eixample $(16,4 \%)$. Está teniendo lugar, pues, una extensión de la inmigración a todos los barrios de la ciudad, una dispersión producida no sólo por el aumento de la población extranjera en sí mismo, sino también por la saturación urbanística de la ciudad y la dificultad en el acceso y la transitoriedad de la vivienda.

Por zonas estadísticas (hay 38), la zona estadística donde hay un mayor número de extranjeros de Barcelona, es en Raval, Esquerra Eixample, Sants, Gracia y Sant Gervasi. Y las zonas donde tienen más peso relativo (respecto al total de la población) son el Raval (donde el $47 \%$ de la población empadronada es extranjera), Parc (35\%), Gòtic (32\%), Trinitat Vella (29\%), Poble Sec (27\%), Barceloneta (25\%) y Ciutat Meridiana-Vallbona (24\%). Los barrios del Raval y Poble Sec, donde se está realizando investigación etnográfica, acogen a gran parte de la población extranjera de la ciudad (véase la FIGURA 6).

\footnotetext{
${ }^{3}$ Hay que tener en cuanta que la Ley del Padrón permite el empadronamiento de personas sin domicilio fijo. En Barcelona, a efectos puramente administrativos se les asigna la dirección de las dependencias municipales de Ciutat Vella, lo que afecta a esta cifra.
} 


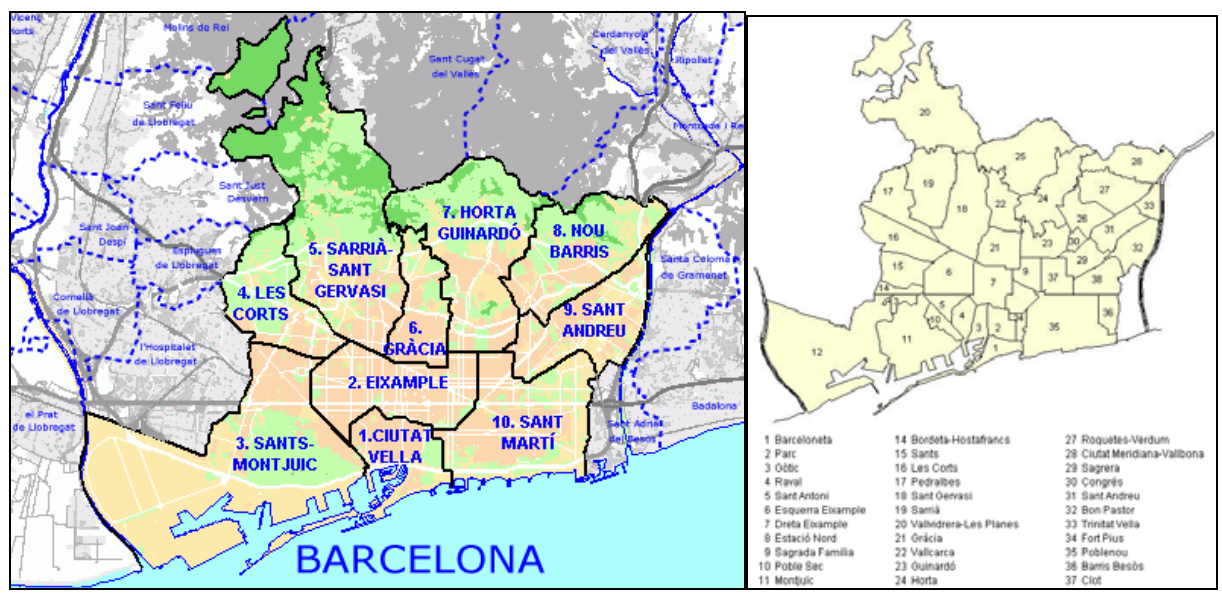

FIGURA 6. División territorial de Barcelona según el Distrito (izquierda), y según la Zona Estadística Grande (derecha). Fuente: Departamento de Estadística del Ayuntamiento de Barcelona

Como ya se ha dicho anteriormente, hay municipios donde la densidad de población extranjera es mucho más alta que en Barcelona. Este es el caso, por ejemplo, de Hospitalet del Llobregat, dentro de la provincia de Barcelona, que a principios de 2006 registraba 41.712 residentes extranjeros, casi el $17 \%$ de su población total, y se va perfilando no sólo como uno de los municipios con más población extranjera de Cataluña, sino también como una de las ciudades con más densidad de población extranjera de España y de Europa, ya que, aunque el aumento de la inmigración ha seguido un ritmo exponencial en toda Cataluña, en el municipio de Hospitalet de Llobregat el ritmo ha sido aún mayor: una media de 400 nuevos extranjeros extra-comunitarios por semana, especialmente en el barrio de Collblanc-Torrassa, el escogido para realizar investigación etnográfica dentro del proyecto que aquí se presenta. Esta rapidez en el cambio de escenario ha hecho que las estructuras de cobertura social se hayan visto desbordadas. En cuanto al ámbito de la salud, concretamente, hay una demanda muy por encima de la disponibilidad de médicos y profesionales de la salud. Faltan, pues, infraestructuras e instrumentos legales para gestionar esta nueva realidad.

Esta situación es parecida a otros municipios de Barcelona, como por ejemplo Terrassa, donde la importante inmigración interior, fundamentalmente procedente de Andalucía, de los años 1960s y 1970s ha dado paso a un incremento también sin precedentes de inmigración extranjera. Concretamente, el barrio de Ca n'Anglada, escogido para realizar la investigación etnográfica, tiene actualmente un porcentaje de población extranjera de más del $30 \%$. 
Finalmente, todavía dentro del contexto barcelonés, la comarca de Osona se ha convertido en uno de los principales polos de atracción de la inmigración en el conjunto de Cataluña. Actualmente el $13 \%$ de su población es extranjera, gracias a la creciente vitalidad económica de la comarca, caracterizada por la diversidad de oportunidades y la existencia de sectores en expansión, entre los cuales destacan muy especialmente las industrias cárnicas, la construcción y la hostelería. Estos sectores se caracterizan (especialmente el de las cárnicas) por una oferta de lugares de trabajo poco cualificados y con unas condiciones a menudo muy duras, que acostumbran a ser rechazados por los jóvenes autóctonos y se convierten en un reclamo para los inmigrantes. Los municipios de Vic y Manlleu concentran la mayor parte de la inmigración de la comarca, de hasta 53 países diferentes, pero especialmente la procedente de Marruecos (véase, más arriba, la Figura 5).

Saliendo de la provincia de Barcelona, encontramos municipios donde la situación es estructuralmente la misma: en Tortosa (Tarragona), por ejemplo, donde también se está realizando investigación etnográfica (con gitanos rumanos), hay representadas actualmente 91 nacionalidades extranjeras distintas. Rumania, con 1.147 individuos (644 hombres y 503 mujeres) es la tercera, después de Marruecos y Pakistán, según datos provisionales para 2007.

Finalmente, diversos municipios de la provincia de Girona hace años que están a la cabeza en acogida de inmigración extranjera. De hecho, Girona es la provincia con más densidad de población extranjera de Cataluña (17\%, muy por encima de la media de Cataluña). En esta provincia, municipios como Salt han pasado han pasado de acoger una importante inmigración interna (andaluza) durante los años 1970s, a ser uno de los municipios de Cataluña con más población extranjera, especialmente de países africanos, y en particular de Marruecos (el 45\% de la población extranjera) y Gambia (32\%). Como en otros de los casos mencionados, también la densidad de población extranjera de este municipio, actualmente del $32,2 \%$, es sobresaliente.

En cuanto a los colectivos seleccionados, sus características y distribución, en primer lugar podemos señalar que casi todos ellos tienen una presencia importante en el territorio, aunque hay grupos que se concentran más en determinadas provincias, municipios y barrios (véase la Figura 7). Los trabajos etnográficos se están realizando teniendo en cuenta esta distribución. 


\begin{tabular}{llllllll} 
& $\begin{array}{l}\text { Total } \\
\text { Extranjeros }\end{array}$ & Pakistán & Rumania & Marruecos & Gambia & Senegal & $\begin{array}{l}\text { Guinea } \\
\text { Ecuatorial }\end{array}$ \\
\hline CATALUÑA & 913.757 & 25.728 & 51.353 & 188.604 & 14.329 & 12.563 & 1.334 \\
Barcelona & 645.737 & 23.470 & 20.364 & 118.795 & 5.648 & 6.643 & 1.035 \\
Girona & 116.284 & 344 & 6.878 & 31.144 & 7.418 & 2.122 & 53 \\
Lleida & 52.633 & 162 & 9.961 & 11.830 & 1.149 & 1.986 & 131 \\
Tarragona & 99.103 & 1.752 & 14.150 & 26.835 & 114 & 1.812 & 115 \\
\hline
\end{tabular}

FIGURA 7. Población extranjera por nacionalidades seleccionadas en Cataluña y provincias a 1/1/2006. Fuente: Padrón Municipal de Población 2006, INE. Elaboración propia.

Uno de los aspectos más destacables en cuanto al perfil sociodemográfico de los colectivos seleccionados, es que presentan una gran heterogeneidad, con características bien diferenciadas entre ellos, tanto en cuanto al momento de llegada al territorio y el proyecto migratorio, como por sus características sociodemográficas (edad, distribución por sexo, etc.) y culturales (religión y sistema de creencias, modelos de representación de la persona y del cuerpo, prácticas alimenticias, rituales y prácticas medicinales tradicionales, estructura y apoyo familiar, etc.). Esta heterogeneidad debe tenerse en cuenta al considerar los procesos de atención a la salud en la sociedad de acogida.

Los pakistaníes, por ejemplo, son un colectivo con una presencia relativamente reciente en Cataluña, con una distribución por sexo muy masculinizada (casi el $90 \%$ son hombres), jóvenes (el 60\% son adultos de 25-39 años de edad), la gran mayoría con estudios primarios, y con una alta concentración y segregación espacial, a diferencia de otros colectivos, como los latinoamericanos. La mayoría de pakistaníes proviene de la región del Punjab, y vive en el municipio de Barcelona (14.251 individuos, a 1 de enero de 2006), entre el distrito de Ciutat Vella y el de Sants-Montjuïc, especialmente en el barrio (zona estadística) de Poble Sec y el del Raval. El 40\% lleva menos de un año en la ciudad, y el $45 \%$ entre uno y cinco años. Otras características socioculturales particulares de la población procedente de Pakistán, además del predominio de los hombres y la afiliación religiosa mayoritaria al Islam, es una actividad laboral con un nicho económico inicialmente muy definido: los bazares de electrónica y souvenirs. Son precisamente las estrategias económicas comunitarias ("negocios étnicos") las que explican en gran medida la concentración residencial de este colectivo. 
La población inmigrada marroquí, aunque tiene rasgos socioculturales comunes con los pakistaníes, senegaleses y gambianos (Islam, aspectos alimentarios, aspectos de los modelos de organización de la procreación, etc.) tienen una presencia mucho más prolongada en Cataluña, y están mucho más dispersos en el territorio (en las cuatro provincias e internamente, dentro de cada municipio). Por ejemplo, en Barcelona, donde a 1 de enero de 2006 se registraban 15.522 individuos de nacionalidad marroquí, no sólo tenían una presencia importante en los distritos con más población inmigrante, como Ciutat Vella (4.468), sino también en los distritos de Sants-Montjuïc (2.513, 1.153 de estos en Poble Sec), Sant Martí (1.858), Nou Barris (1.347) y Sant Andreu (1.285). La población marroquí también tiene una presencia muy importante en la comarca de Osona, y en particular en los municipios de Vic y Manlleu, que es donde se concentra la mayor parte de la inmigración de la comarca, y donde se está realizando investigación etnográfica con esta población. En Manlleu, por ejemplo, a pesar del aumento en la multiplicidad de procedencias de los últimos años, los extranjeros de nacionalidad marroquí son los más numerosos con diferencia. A fecha de 1 de enero de 2006 había registradas 3.229 personas de nacionalidad marroquí, que representan el $80 \%$ del total de extranjeros (4.083 personas, en números absolutos). Como en los demás grupos, también aquí hay que tener en cuenta la heterogeneidad interna del colectivo. En Manlleu en concreto, a diferencia de otros municipios, se trata de personas de origen rural procedentes fundamentalmente de Nador (en las montañas del Rif), con unas características socioculturales diferenciadas, como por ejemplo, el hecho de no tener como lengua propia el árabe, sino una de las lenguas amazigh (la etnia mayoritaria de esta región), que tiene un registro sobre todo oral. El relativo asentamiento de una primera colonia de inmigrantes marroquíes, durante principios de los 1990s, mayoritariamente hombres procedentes de esta región del país norteafricano, ha dado lugar a la consolidación de cadenas migratorias y el asentamiento consolidado de este origen. En el barrio del Erm, que es donde se está realizando trabajo etnográfico con población marroquí, es donde reside el $42,5 \%$ de los extranjeros de Manlleu (1.830 personas, en números absolutos). De hecho, el porcentaje de extranjeros que hay en este barrio es del $55,5 \%$, es decir, un porcentaje que supera el de población de nacionalidad española. Y el 51\% de estos extranjeros es de nacionalidad marroquí (1.681 personas, en números absolutos). Finalmente, la 
diversificación de los marroquíes también se traslada al ámbito laboral, en los diferentes sectores de actividad, y su ratio por sexo es más equilibrada que la de los pakistaníes, y también que la de los colectivos subsaharianos, como Senegal y Gambia, dada su presencia más prolongada en Cataluña. A pesar de esto, el porcentaje de hombres, especialmente en las edades adultas, es aún mayor que el de mujeres.

Las poblaciones inmigradas procedentes del África subsahariana, tienen también características sociodemográficas diferenciadas. Senegal y Gambia representan el $60 \%$ del total de población de países del África subsahariana, aunque hay otros países, como Guinea Ecuatorial, con fuertes vínculos históricos (coloniales) con España. Los ecuatoguineanos, han estado emigrando hacia Cataluña desde los años 1950s, esencialmente después de 1969, con el golpe de estado frustrado contra la dictadura de Macias. La inmigración guineana es, pues, la más antigua de procedencia no europea. Gran parte de la población inmigrada de Guinea Ecuatorial es poco visible estadísticamente, debido a que la mayoría tiene la nacionalidad española y algunos están en situación de irregularidad. Este hecho nos permite el análisis de su proceso migratorio en momentos muy diferenciados de su historia migratoria, donde han predominado distintos factores para la migración (estudios, refugio político, visita familiar, atención sanitaria, trabajo y mejora de condiciones de vida, etc.), los cuales han influido de maneras diversas en su proceso de integración social en Cataluña. Si al principio la emigración de esta población consiguió la nacionalidad española y optó por adquirir un buen nivel de estudios e incorporarse en el mercado laboral de la sociedad de destino (fundamentalmente como profesionales de los sectores secundario y terciario), las migraciones más recientes (sobre todo de los años 1990s) están motivadas principalmente por la búsqueda de recursos económicos, sin que su situación esté siempre regularizada. Cabe añadir que, a diferencia de la mayoría de grupos procedentes de África, donde predomina la afiliación al Islam, muchos ecuatoguineanos son cristianos; aunque en el contexto de una gran diversidad religiosa y étnica (Annoboneses, Bubi, Fang y Ndowé son las etnias principales). Los ecuatoguineanos se han asentado principalmente en las áreas más urbanas de la provincia de Barcelona, y en general se diferencian del resto de colectivos africanos 
por el hecho de que disponen de un nivel socioeconómico y educativo alto, además de ser el único grupo que habla castellano como lengua propia.

Los senegaleses y gambianos, y también los inmigrantes procedentes de Nigeria, Sierra Leona, Zaire o Camerún, han llegado más recientemente a Cataluña, sobre todo a partir de finales de los 1970 s, con una primera oleada importante en los años 1980s, y una segunda mucho más reciente, con características bien distintas (niveles socio-educativos más bajos, población en situación irregular, etc.). A pesar del aumento en los últimos años de la reagrupación familiar y de las migraciones de mujeres con proyectos migratorios independientes, la mayoría de senegaleses y gambianos en Cataluña son hombres jóvenes, de religión musulmana, ocupados fundamentalmente en el sector de servicios, la agricultura de temporada y la construcción; aunque a la vez mantienen una amplia y diversificada economía sumergida, con incipientes negocios étnicos y transnacionales.

A pesar de las similitudes, hay que tener en cuenta también la heterogeneidad entre los colectivos de Gambia y Senegal, tanto en cuanto a los momentos de llegada a Cataluña (más reciente en el caso de los senegaleses), el origen (rural y urbano), los grupos étnico-lingüísticos, o la distribución territorial: mientras que los senegaleses se concentran en la provincia de Barcelona, los gambianos se distribuyen entre Barcelona y Girona, donde son incluso más numerosos. Cabe destacar también que la estructura de la población por sexo, especialmente en el caso de la población gambiana, está muy masculinizada, especialmente en las edades adultas.

Los inmigrantes procedentes de Rumania tienen una presencia todavía más reciente en nuestro territorio que los orígenes asiáticos. ${ }^{4}$ En España, han pasado de ser poco más de 6.000 personas en el año 2000 a más de 400.000 en 2006 (524.995 a 1 de enero de 2007, según datos provisionales del Padrón), y en Cataluña son ya 51.353 individuos, ocupando la tercera posición en el ranking de nacionalidades extranjeras, sólo por detrás de Marruecos y Ecuador.

A diferencia de otros grupos inmigrantes, como los pakistaníes, chinos, o incluso marroquíes, que proceden mayoritariamente de alguna región concreta de su país, las zonas de procedencia de la población rumana son muy diversas: tanto rurales como urbanas; de las provincias centrales, del sur, del oeste y del sudoeste.

\footnotetext{
${ }^{4}$ Sobre inmigrantes rumanos en España, véase Pajares, M. (2007).
} 
Hay, sin embargo, municipios donde predomina un origen concreto, como es el caso de Castelldefels, en la provincia de Barcelona, donde hay un número importante de población de nacionalidad rumana (1.153) y que en su mayoría proviene del distrito de Alba, en la región de Transilvania, en la zona centro-occidental de Rumanía. Los rumanos se concentran en las provincias de Barcelona y Tarragona, con actividades ocupacionales diversificadas según el destino (recogida temporal de fruta, construcción, etc.). Su ratio por sexo es la más equilibrada de todos los grupos seleccionados, pues, a diferencia de otros grupos, la inmigración de mujeres, tanto vinculadas a proyectos migratorios dependientes como con proyectos migratorios independientes, es muy importante. Aquí debemos contar la inmigración de mujeres jóvenes relacionada con redes de explotación laboral y sexual (prostitución), que ha aumentado en los últimos años. A pesar de la concentración en las provincias de Barcelona y de Tarragona, hay municipios en otras provincias, como en la ciudad de Lleida o Balaguer, donde hay un número importante de rumanos (2.404 y 829, respectivamente). Los datos para el municipio de Barcelona a 1 de enero de 2006 indican una presencia de población rumana en la mayoría de los distritos, especialmente. Los datos de 1 de enero de 2006 para el municipio de Barcelona, donde constaban 4.704 individuos de nacionalidad rumana (en 1996 eran sólo 78), señalan que tienen una presencia importante en la mayoría de distritos, especialmente en Ciutat Vella (820), Sants-Montjuïc (640, 138 en Poble Sec), Sant Martí (615), Nou Barris (567), Eixample (567), y Horta-Guinardó (507). Dentro de la provincia de Barcelona, hay también un número importante de rumanos en el municipio de Hospitalet del Llobregat (839) y en Badalona (1.136).

El colectivo gitano también tiene características bien diferenciadas del resto de grupos. En el caso de los gitanos catalanes y originarios de otras zonas del Estado, no se trata de población inmigrante o extranjera, sino de una minoría étnica con características culturales propias (la cultura 'rom'), y con una presencia en Cataluña que, en algunos casos, se remonta a hace más de 500 años. Esto hace que su visibilidad estadística sea muy limitada. En el año 2006 se calcula que vivían en Cataluña unas 80.000 personas de etnia gitana, que representan el 1,2\% de la población catalana y el $12 \%$ de la comunidad gitana de todo el Estado (unos 600.000). Los gitanos que llevan más tiempo en Cataluña, "gitanos catalanes", se localizan en barrios céntricos de las ciudades o municipios donde residen. Los 
procedentes de las migraciones interiores de los años 1950s y 1960s, en cambio, están localizados en los barrios construidos con el expansionismo de las grandes ciudades o municipios muy cercanos a la capital de provincia. La mayoría viven en la provincia de Barcelona y, entre ellos, los gitanos catalanes lo hacen mayoritariamente en los distritos de Sants-Montjuïc (en particular en BordetaHostafrancs), la calle de la Cera y proximidades (entre los barrios del Raval, en Ciutat Vella, y Sant Antoni, en Eixample), Gracia y Sant Martí; pero también hay grupos numerosos en Girona capital, Lleida, Tarragona y Reus.

A pesar de que en las últimas décadas se ha producido una sensible mejora en sus condiciones de vida, debido al acceso a los sistemas de protección social, a la vivienda pública y a los sistemas de salud y educación, una gran parte de la población gitana continúa constituyendo uno de los grupos más vulnerables y con mayor riesgo de exclusión social y económica de Cataluña, además de ser víctimas frecuentes de prácticas discriminatorias que impiden su acceso a los bienes y servicios en igualdad de condiciones que el resto de los ciudadanos catalanes. Hay características sociodemográficas, como una tasa de natalidad por encima de la media catalana, una tasa de analfabetismo muy alta (60\%), o la problemática de la vivienda (movilidad por desalojo), que indican problemas específicos de cara a la atención en el ámbito de la salud de este colectivo.

Finalmente, en cuanto a los gitanos rumanos, aunque se trata de un colectivo poco voluminoso en términos absolutos comparado con otros grupos (se calcula que son entre 2.000 y 3.000 individuos en Cataluña), es un grupo que tiene características sociodemográficas muy diferenciadas, y que hacen necesario el estudio etnográfico. De entrada, hay problemas de visibilidad estadística, pues no todos los extranjeros rumanos son gitanos. A pesar de las dificultades en la estimación de su número, podemos aproximarnos al hecho de que son un colectivo en crecimiento si consideramos que la mayoría de los 10 millones de población gitana que vive en Europa, lo hace en países de Europa del Este (8 millones), y Rumania es el país con más ciudadanos gitanos (unos 3 millones, que representan más del $9 \%$ de la población total). A diferencia de la inmigración rumana no-gitana, que procede de la mayoría de regiones y provincias de Rumania, la mayoría de los gitano-rumanos que hay en Cataluña proviene de unos pocos lugares, particularmente de la provincia de lalomita, en la región histórica de Valáquia, al sud- 
este de Rumania, y en concreto de poblaciones como Țăndărei y Feteşti. Esta es una zona empobrecida donde la mayoría de la población se dedica al peonaje agrícola e industrial, y a trabajos precarios. Esta situación de pobreza, y de exclusión social histórica, es el incentivo principal para la emigración hacia Cataluña. También existen otros grupos de rrom de Rumania en Cataluña provenientes de otras zonas y localidades, como Timişoara (provincia de Timiş, región de Banat) y Murgeni (provincia de Vaslui, región de Moldova). Respecto a su distribución por el territorio, el municipio donde hay más presencia de gitanos rumanos es en Badalona, ciudad contigua a Barcelona, especialmente en el barrio de Sant Roc (fundamentalmente procedente de lalomita), y también en el barrio de Fondo, en Santa Coloma de Gramanet, que es la zona limítrofe con Badalona, donde hay una mayor proporción de rrom de Murgeni. En segundo término, en Tortosa (Tarragona), la mayor parte de la población rrom rumana es originaria de Timişoara. También hay una presencia significativa en el área metropolitana de Barcelona (Hospitalet de Llobregat, principalmente en los barrios de Collblanc, Pubilla Casas y la Torrassa), y en diversos barrios de la ciudad de Barcelona de los distritos de Horta-Guinardó, Sant Martí, Sant Andreu y Sants-Montjuïc. La investigación etnográfica se está llevando a cabo en varios de estos barrios.

Como el resto de colectivos seleccionados, los gitanos rumanos, y en general los rrom de Europa del Este, son un colectivo muy heterogéneo, pero que a menudo se homogeniza, bien por los estereotipos que acentúan los medios de comunicación, bien por la confusión con otros grupos (no todos los gitanos del Este son rumanos, ni tampoco todos se encuentran en la misma situación). Existen multitud de subgrupos basados en distinciones étnicas, lingüísticas u ocupacionales. Un rasgo común, sin embargo, es la organización familiar, que corresponde al modelo de familia extensa patrilineal, con diferentes generaciones dentro de la misma vivienda, y con roles de género muy diferenciados. Cabe mencionar también el recurso a la mendicidad y las condiciones de infravivienda y exclusión social, que afectan particularmente a este colectivo, sobre todo en el área metropolitana de Barcelona, algo que habrá que tener muy en cuenta a la hora de analizar el acceso y las condiciones de uso de los servicios sanitarios.

\section{Conclusiones preliminares}


En este artículo se ha presentado un proyecto de investigación en curso, que trata de comprender la conjunción de las situaciones socio-económicas y los factores culturales correspondientes a diferentes segmentos en condiciones socioeconómicas vulnerables de diversos colectivos inmigrados y minorías étnicas que tienen una presencia importante en algunos de los barrios de actuación prioritaria implicados en el Programa Salud Barrios del Departamento de Salud de la Generalitat de Catalunya, y que están llevando a cabo miembros del GRAFO (Grupo de Investigación en Antropología Fundamental y Orientada) de la Universidad Autónoma de Barcelona. Se trata, esencialmente, de analizar los factores que afectan a su salud, al acceso a los servicios sanitarios y a la relación que mantienen con ellos y con el personal sanitario que los atiende. Aunque es todavía demasiado pronto para avanzar cualquier tipo de conclusión, se pueden señalar algunas reiteraciones extraídas tanto del análisis de informes ya existentes como de la información preliminar del trabajo etnográfico en marcha:

a. La inmigración en los últimos años ha cambiado de forma sustancial el panorama de asistencia en salud en Cataluña. En este contexto, los profesionales de la salud reclaman más recursos y formación para abordar esta situación.

b. Faltan recursos y mayor coordinación entre las administraciones y los agentes sociales, así como canales de información y de conexión y diálogo.

c. Entre los inmigrantes puede haber una mayor incidencia de problemas de salud relacionados con la salud sexual, reproductiva y materno-infantil, así como enfermedades infecciosas y parasitarias [En algunos tipos de fuentes bibliográficas no parece existir suficiente información epidemiológica que respalde esta reiteración. Los resultados de distintos estudios son a veces contradictorios entre sí; y muchos estudios tienen importantes limitaciones metodológicas, como por ejemplo estar basados en población en situación marginal extrema; o sólo en los que van a determinados servicios. Otros sesgos metodológicos tienen que ver con aspectos sociodemográficos: por ejemplo, el hecho de que los inmigrantes hagan más uso de las consultas de ginecología y pediatría que la población autóctona se explica, sobre todo, por 
el perfil de esta población: jóvenes en edad fértil, frente a la media de edad más avanzada de la población autóctona]

d. Hay muchas dificultades de acceso a los servicios de salud y seguimiento de los tratamientos por parte de la población inmigrada y minorías étnicas, por diversas razones: carencia de la tarjeta sanitaria (en parte por problemas en los empadronamientos); desconocimiento del sistema (también uso incorrecto); miedo debido a la situación de irregularidad (junto a carencia redes de apoyo); movilidad o desplazamiento; diferentes formas de percibir y en los usos en relación con la salud (incluye la percepción de la salud como algo secundario, frente al trabajo y la vivienda); problemas de comunicación (explicación y diagnóstico) médico/paciente (idioma, analfabetismo, distancia en roles de género, prejuicios, diferencias de conceptualización e interpretación o, directamente discriminación).

e. La situación de exclusión socioeconómica y de irregularidad administrativa son factores que influyen de forma crucial en las desigualdades en salud de los inmigrantes.

La forma en que se ha concebido este proyecto, su diseño y su ejecución, se inscribe plenamente en la forma en la que el GRAFO concibe el método científico en antropología, y la antropología básica, fundamental, orientada y aplicada ${ }^{5}$. En cuanto a lo primero, se parte de una idea de método científico en antropología basada en la puesta a prueba mediante procedimientos de contrastación; en la crítica constante hacia el proceso y el producto de la investigación; en la relación entre teoría y práctica; en la necesidad de trascender las limitaciones de las aproximaciones positivistas (determinismo social) y también de las interpretativas (centradas en los significados; y que llevado a último término plantea que sólo es posible interpretar y, por tanto, que no es posible aplicar el conocimiento a la explicación y solución de fenómenos sociales); y en la capacidad de la antropología de generar un conocimiento riguroso, nunca infalible sino provisional y con mayor o menor grado de validez, pero con capacidad de explicar y predecir y, por tanto, de ser útil o, como decía Lévi-Strauss, de actuar algo menos mal porque se comprende algo mejor. En cuanto a lo segundo, y en relación con lo primero, se parte de la necesidad de una

\footnotetext{
${ }^{5}$ Véanse: San Román, T. (2006) y González Echevarria, A. (2003). 
fundamentación metodológica rigurosa; del compromiso teórico y ético de uso social del conocimiento antropológico y etnográfico; de la necesidad del conocimiento del entramado sociocultural y de su contexto; y de la visión crítica bien fundamentada de la realidad analizada, que implica poner el conocimiento obtenido al servicio de la negociación de los múltiples intereses y necesidades. En el caso concreto del proyecto en curso descrito en este artículo, que se basa fundamentalmente en el trabajo etnográfico, se ha empezado con un estudio teórico y sociodemográfico inicial, para luego preparar de forma minuciosa, antes de la entrada en el campo, los guiones etnográficos con los ítems diseñados en función de los objetivos del proyecto. El trabajo etnográfico se está llevando a cabo con una selección de los barrios y grupos más pertinentes para el estudio (en este caso, los más cultural y socialmente inaccesibles) en los que trabajan etnógrafos que son ya competentes en esos colectivos; de manera que, con la asesoría del equipo de dirección y coordinación, pueden abordar de forma más precisa y sin pérdida de contexto, de significados ni de relaciones causales entre fenómenos diversos, los aspectos de interés para el proyecto. A la fase etnográfica le seguirá una fase de análisis de conjunto de los datos procedentes tanto de los informes ya existentes de la administración y entidades como de la información etnográfica obtenida (análisis de conjunto y puesta a prueba de las conclusiones de unos barrios en otros). Esta última fase del proyecto dará lugar a un informe final de conclusiones, previsto para julio de 2008, en la parte etnográfica y de contrastación, y noviembre de 2008 en la de recomendaciones, elaboración de instrumentos. Esta etapa final incluye la preparación de materiales, guías orientativas, propuesta de categorías para la investigación, protocolos de introducción de datos, advertencias, interlocución y formación de personal sanitario, y que considera la participación activa de las propias poblaciones implicadas a medio y largo plazo. En este sentido, el trabajo etnográfico juntamente con la reflexión y la contrastación sobre y a través de la práctica clínica, deben permitir mejorar este conocimiento y cumplir con el objetivo de fondo del proyecto, que es orientar mejor la atención sanitaria y dotar a los profesionales de instrumentos conceptuales y prácticos para la detección de problemas, la prevención y resolución de conflictos, la mejora de la comunicación profesional intercultural y la participación real comunitaria. 
En suma, se trata de un proyecto hecho por personas que creen que la Antropología es capaz de generar conocimiento aplicable, y que esto sirve a la construcción y transformación social. Esto es, o debería ser, de hecho, parte de la exigencia ética y de la responsabilidad social de nuestra disciplina.

\section{Referencias $^{6}$}

Domingo, A. y Gil, F. (2006). L'evolució recent de la població estrangera a Catalunya. En l'Estat de la immigració a Catalunya. Anuari 2005. Larios, M. J. y Nadal, M. (Dirs.). Barcelona: Fundació Jaume Bofill.

González Echevarria, A. (2003) Crítica de la singularidad cultural. Barcelona: Anthropos.

Pajares, M. (2007) Inmigrantes del Este: Procesos migratorios de los rumanos. Barcelona: Icaria.

San Román, T. (2006). ¿Acaso es evitable? El impacto de la Antropología en las relaciones e imágenes sociales, Revista de Antropología Social, 15: 373-411.

\footnotetext{
${ }^{6}$ El presente artículo ofrece una bibliografía sobre salud e inmigración disponible abiertamente para su consulta en la siguiente dirección URL: http://www.aibr.org/antropologia/02v03/articulos/020303b.pdf
} 